\title{
AUTOMEDICAÇÃO EM CRIANÇAS DE ZERO A CINCO ANOS: FÁRMACOS ADMINISTRADOS, CONHECIMENTOS, MOTIVOS E J USTIFICATIVAS
}

Self-medication in children from zero to five years: farmacos managed, knowledge, statement and background

La automedicación en niños de cero a cinco años: fármacos administrados, conocimientos, declaraciones y justificativas

Assis do Carmo Pereira Júnior²

\section{RESUMO}

Realizou-se a análise dos fármacos administrados, conhecimentos, motivos e justificativas dos pais e/ou responsáveis em relação à automedicação em crianças. Trata-se de um estudo descritivo, desenvolvido em uma Estratégia de Saúde da Família de um município do interior do estado de Minas Gerais, do qual fizeram parte pais e/ou responsáveis pelas crianças em faixa etária de zero a cinco anos, no período de um mês, atingindo o quantitativo de 50 indivíduos. Destacaram-se a autoadministração dos fármacos Dipirona, Paracetamol e xaropes expectorantes. Foram registrados os conhecimentos errôneos 32(64\%), seguidos dos parciais $11(22 \%)$ e corretos $7(14 \%)$. Como motivos, foram constatados os sintomas de febre, com $29(58 \%)$ dos relatos e as justificaticas foram o costume de administrar tais medicamentos e o fato de já estarem disponíveis no domicílio. Faz-se necessária a implementação de estratégias objetivando conscientizar os pais e/ou responsáveis acerca dos problemas oriundos da automedicação.

Palavras-chave: Erros de medicação. Automedicação. Criança. Enfermagem. Família.

\begin{abstract}
We carried out the analysis of drugs administered, knowledge, motives and justifications of parents and/or guardians in relation to self-medication in children. It is a descriptive study, developed in Estratégia de Saúde da Família in a city in the interior of Minas Gerais, which includes parents and/or guardians of children aged zero to five years, in the period one month, reaching the amount of 50 individuals. The highlights were the self administration of drugs Dipyrone, Paracetamol and syrups expectorants, erroneous knowledge $32(64 \%)$, followed by partial $11(22 \%)$ and correct 7 (14\%), respectively, the symptoms of fever with $29(58 \%)$ of the reasons and justification that they are accustomed to administer such drugs and they already have them at home. It is necessary to implement strategies focused in educate parents and/or guardians about the problems arising from self-medication.
\end{abstract}

Keywords: Medication Errors. Self Medication. Child. Nursing. Family.
Se realizó el análisis de los fármacos administrados, conocimientos, motivaciones y justificativas de los padres y/o tutores en relación a la automedicación en niños. Se trata de un estudio descriptivo, desarrollado en una Estrategia de Salud para la Familia de un municipio en el interior del estado de Minas Gerais, que incluye a los padres y/o tutores de los niños de cero a cinco años en el período de un mes, alcanzando la cifra de 50 personas. Lo más destacado fue la autoadministración de drogas Dipirona, Paracetamol y jarabes expectorantes, el conocimiento erróneo 32 (64\%), seguido de los parciales 11 (22\%) y de los correctos 7 (14\%), respectivamente, los síntomas de la fiebre con 29 (58\%) de los motivos y la justificativa que se utiliza para administrar medicamentos, y ya tienen en casa. Es necesario implementar estrategias dirigidas a la concientización de los padres y/o tutores acerca de los problemas derivados de la automedicación.

Palabras clave: Errores de Medicación. Automedicación. Niños. Enfermería. Familia.

\footnotetext{
${ }^{1}$ Enfermeiro. Doutor em Enfermagem Fundamental pela Escola de Enfermagem de Ribeirão Preto-Universidade de São Paulo (EERP-USP). Professor Adjunto IV do Departamento de Enfermagem da Universidade Federal dos Vales do Jequitinhonha e Mucurí (UFVJM). Diamantina-MG. Brasil. E-mail: ppradotelles@yahoo.com.br; ${ }^{2}$ Enfermeiro. Especialista em Saúde Coletiva pela Escola de Enfermagem da Universidade Federal de Minas Gerais (UFMG). Professor Substituto do Departamento de Enfermagem da UFVJM. Diamantina-MG. Brasil. E-mail: assisdocarmo@yahoo.com.br
} 


\section{INTRODUÇÃO}

Atualmente, o tema relacionado à automedicação tem sido abordado na literatura, mas carecem estudos que identifiquem fatores pertencentes ao contexto pediátrico e favoreçam a criação e implementação de medidas voltadas à prevenção de agravos nesta população'.

A automedicação movimentou, aproximadamente, oito bilhões de reais em 2008, o que corresponde a $30 \%$ de todo o mercado farmacêutico no Brasil. 0 fármaco é um símbolo de saúde, mas a crença, que persiste há anos, de que existe a total cura das mais diversas patologias por meio das cápsulas ou pílulas é equivocada. 0 seu uso indiscriminado pode levar ao agravamento do estado de saúde do paciente, intoxicação ou, até mesmo, à morte? .

A automedicação é definida como a utilização de fármacos sem prescrição, com o objetivo de tratar ou aliviar sintomas ou mesmo de promover a saúde, independente da prescrição. Muitos desses fármacos são utilizados de forma inadequada; destacam-se os problemas relacionados ao uso de antibióticos para tratar infecções de etiologia viral, a utilização de fármacos cuja efetividade não está comprovada, além de problemas como erros na dosagem, intervalo de administração e tempo de utilização ${ }^{3}$.

Atualmente muitos dos responsáveis pelas crianças empregam a automedicação para alívio dos sintomas como cefaleia, resfriado e dor, recorrendo a farmácias domiciliares, as quais contêm analgésicos, antigripais e anti-inflamatórios que podem representar risco para as crianças ${ }^{4}$.

As farmácias domiciliares, frequentemente depositadas em ambientes e recipientes inadequados, propiciam o consumo irracional e o desperdício, incluindo a facilitação da automedicação não responsável, bem como 0 aumento do risco de exposições tóxicas, principalmente em crianças ${ }^{5}$.

Outro aspecto a ser destacado na autoadministração de fármacos em crianças é a utilização abusiva de embalagens atraentes, medicamentos coloridos e adocicados, com sabor de frutas e formatos de bichinhos, colaborando sobremaneira para o aumento das intoxicações acidentais $^{6}$.

Dados do Sistema Nacional de Informações Tóxicos-farmacológicos mostram que a utilização elevada de fármacos desde a tenra idade é preocupante, citando que as intoxicações por medicamentos elevaram-se de 15\% em 2000 para $29 \%$ em 2004 e que as crianças menores de cinco anos destacam-se em quantitativo de vítimas (35\% dos casos). Em 2007, os fármacos foram a causa mais frequente de intoxicação no Brasil?.

Diante da importância do cenário descrito, propôsse a realização deste estudo cujo objetivo foi analisar os fármacos administrados, conhecimentos, motivos e justificativas dos pais e/ou responsáveis em relação à automedicação em crianças.

\section{MÉTODO}

Trata-se de um estudo descritivo, ou seja, aquele que visa descrever as características de determinada população ou fenômeno, ou o estabelecimento de relações entre as variáveis e que utiliza técnicas padronizadas de coleta de dados, dentre elas o questionário ${ }^{8}$.

0 estudo foi desenvolvido na Estratégia de Saúde da Família (ESF) Renascer, localizada no interior de um município do Estado de Minas Gerais. A unidade compõe-se de um enfermeiro, um médico, dois técnicos de enfermagem e seis agentes comunitários de saúde e constitui campo de prática para os cursos da área da saúde de uma universidade federal.

Fizeram parte do estudo os pais e/ou acompanhantes responsáveis pelas crianças entre a faixa etária de zero a cinco anos, cadastradas na ESF, atingindo o quantitativo de 50 indivíduos. A coleta de dados foi realizada após a aprovação do estudo pela Secretaria de Saúde do Município e pelo Comitê de Ética da Universidade Estadual de Montes Claros, sob o número de protocolo: 2769/2011.

Foi utilizado um questionário adaptado ${ }^{9}$ para coleta dos dados, constituído de perguntas estruturadas contendo dados de identificação e referentes à automedicação: "Você dá medicamento sem prescrição para sua criança?", "Quais medicamentos?", "Em relação aos medicamentos administrados, o que você conhece?", "Por quais motivos?" e "Por que não compareceu ao serviço de saúde antes de fazer uso da automedicação?".

A discussão foi baseada em artigos nacionais e internacionais sobre a temática e deu-se através da análise descritiva.

Vale ressaltar que os participantes receberam explicações sobre o projeto, e somente fizeram parte do estudo os indivíduos que concordaram em participar, por meio de assinatura do Termo de Consentimento Livre e Esclarecido para Participação em Pesquisa. Os aspectos éticos de confiabilidade e privacidade foram assegurados de acordo com a Resolução n 196/96, sobre pesquisa que envolve seres humanos ${ }^{10}$.

\section{RESULTADOS}

É oportuno afirmar que foram aplicados questionários a 63 pais e/ou responsáveis. Entretanto, 13 destes não praticam a automedicação; portanto, a amostra deste estudo foi composta por 50 indivíduos.

Os dados de identificação das crianças e dos pais e/ou responsáveis são apresentados na Tabela 1. 
Automedicação em crianças de zero a cinco anos

Tabela 1 - Distribuição dos dados de identificação das crianças e dos pais e/ou responsáveis.

\begin{tabular}{|c|c|c|c|c|c|c|}
\hline \multicolumn{7}{|c|}{ Dados de identificação } \\
\hline \multirow{2}{*}{$\begin{array}{l}\text { Faixa etária das } \\
\text { crianças }\end{array}$} & Menos de um ano & Um ano & Dois anos & Três anos & Quatro anos & Cinco anos \\
\hline & $3(6 \%)$ & $11(22 \%)$ & $5(10 \%)$ & $12(24 \%)$ & $9(18 \%)$ & $10(20 \%)$ \\
\hline \multirow{2}{*}{$\begin{array}{l}\text { Gênero das } \\
\text { crianças }\end{array}$} & Masculino & Feminino & \multirow{2}{*}{-} & \multirow{2}{*}{--} & \multirow{2}{*}{--} & \multirow{2}{*}{-- } \\
\hline & $32(64 \%)$ & $18(36 \%)$ & & & & \\
\hline $\begin{array}{l}\text { Renda dos pais } \\
\text { e/ou responsáveis }\end{array}$ & $\begin{array}{l}\text { Menor que um } \\
\text { salário mínimo } \\
9(18 \%)\end{array}$ & $\begin{array}{l}\text { Um salário } \\
\text { mínimo } \\
24(48 \%)\end{array}$ & $\begin{array}{c}\text { Dois salários } \\
\text { mínimos } \\
11(22 \%)\end{array}$ & $\begin{array}{l}\text { Três salários } \\
\text { mínimos } \\
6(12 \%)\end{array}$ & & \\
\hline $\begin{array}{l}\text { Escolaridade dos } \\
\text { pais e/ou } \\
\text { responsáveis }\end{array}$ & $\begin{array}{l}\text { Ensino } \\
\text { Fundamental } \\
\text { 19(38\%) }\end{array}$ & $\begin{array}{c}\text { Ensino } \\
\text { Médio } \\
31(62 \%)\end{array}$ & -- & -- & - & -- \\
\hline $\begin{array}{l}\text { Profissões dos } \\
\text { pais e/ou }\end{array}$ & Faxineira & Tecelã & Camareira & Balconista & Lavadeira & $\begin{array}{l}\text { Pintora e } \\
\text { Garimpeira }\end{array}$ \\
\hline responsáveis & $25(50 \%)$ & $9(18 \%)$ & $7(14 \%)$ & $5(10 \%)$ & $3(6 \%)$ & $1(2 \%)$ \\
\hline
\end{tabular}

No que concerne às crianças, destaca-se, portanto, a faixa etária de três anos 12 (24\%), bem como o sexo masculino 32 (64\%). Em relação aos pais e/ou responsáveis houve destaque para a renda de um salário mínimo 24(48\%),
31 (62\%) tinham Ensino Médio como nível de escolaridade e 25 (50\%), a profissão de faxineira.

A automedicação propriamente dita é mostrada na Tabela 2, com os fármacos utilizados pelos pais ou responsáveis.

Tabela 2 - Distribuição dos fármacos autoadministrados.

\begin{tabular}{lcc}
\hline \multicolumn{1}{c}{ Medicamentos } & Quantitativo & $\%$ \\
\hline Dipirona & 27 & 54 \\
Paracetamol & 18 & 36 \\
Xaropes expectorantes & 11 & 22 \\
Amoxicilina & 5 & 10 \\
Simeticona & 2 & 4 \\
Metoclopramida & 1 & 2 \\
\hline Total & 64 & 128 \\
\hline
\end{tabular}

O medicamento Dipirona foi relatado por 27 (54\%) dos entrevistados, seguido pelo Paracetamol, 18 (36\%), e por xaropes expectorantes, 11 (22\%). Entretanto observa-se que os demais fármacos, embora em menor quantitativo, também podem trazer prejuízos às crianças quando autoadministrados, uma vez que os aspectos fisiológicos, farmacocinéticos e farmacodinâmicos tornam as crianças mais suscetíveis aos seus efeitos nocivos.
Justifica-se a porcentagem de 128, uma vez que é autoadministrado mais de um fármaco a cada criança, o que nos remete a interação medicamentosa, que pode potencializar os efeitos terapêuticos, reduzir a eficácia, contribuir para graus distintos de reações adversas ou, ainda, não provocar o efeito desejado.

Os conhecimentos a respeito dos fármacos autoadministrados são apresentados na Tabela 3.

Tabela 3 - Conhecimentos a respeito dos fármacos autoadministrados.

\begin{tabular}{|c|c|}
\hline Medicamentos & Conhecimentos \\
\hline Dipirona & $\begin{array}{l}\text { "Não conheço nada dele não." } \\
\text { "Melhora bastante a irritaçãa quando eu dou esse remédio." } \\
\text { "É muito bom para a febre e resfriado." } \\
\text { "É uma maravilha para tirar a febre dele." }\end{array}$ \\
\hline Paracetamol & $\begin{array}{l}\text { "Sei que ele não faz mal." } \\
\text { "Corta os vermes." } \\
\text { "Não sei nada." } \\
\text { "Ele é antitérmico." }\end{array}$ \\
\hline Xaropes expectorantes & $\begin{array}{l}\text { "Tira todo o catarro do peito dela." } \\
\text { "Ele deixa meu filho mais tranquilo." } \\
\text { "Alivia bastante a tosse dele." } \\
\text { "Eu acho que é bom para o pulmãozinho dele." }\end{array}$ \\
\hline Amoxicilina & $\begin{array}{l}\text { "Mata os bichos que ele tem." } \\
\text { "Ele é bom para tirar a dor do corpo do meu filho." } \\
\text { "Ele ajuda na tosse. Ela para." } \\
\text { "Eu uso para infeçãa, e é muito bom." } \\
\text { "Não sei dizer nada não." }\end{array}$ \\
\hline Simeticona & $\begin{array}{l}\text { "É bom para aliviar os gases." } \\
\text { "Não sei." }\end{array}$ \\
\hline Metoclopramida & $\begin{array}{l}\text { "Ele deixa de ficar enjoado." } \\
\text { "É para enjoo." }\end{array}$ \\
\hline
\end{tabular}


Vale ressaltar que a tabela está descrita de acordo com os fármacos. Entretanto, observando a diversidade e a gravidade dos itens nela descritos, verificou-se a necessidade de categorizá-los de acordo com "conhecimentos errôneos" 32 (64\%), "conhecimentos parciais" 11(22\%) e conhecimentos corretos" 7(14\%).

É extremamente grave que antibióticos e bactericidas sejam autoadministrados sem o conhecimento das indicações de uso, da patologia e sintomatologia, como foi observado nas falas "Não sei dizer nada não." e "Ele é bom para tirar a dor do corpo do meu filho". 0 conhecimento errôneo também foi observado quando se faz uso de antibiótico para sintomatologias não específicas, como observado no relato "Ele ajuda na tosse. Ela para".

Os conhecimentos parciais são observados no uso dos xaropes expectorantes, como nos registros "Tira todo 0 catarro do peito dela", assim como no uso do fármaco Dipirona, "É muito bom para a febre e resfriado".
Embora não seja apropriada a automedicação, observou-se que houve conhecimentos corretos, como nos registros sobre o uso de Simeticona, "É bom para aliviar os gases", Metoclopramida, "É para enjoo", e Paracetamol, "Ele é antitérmico".

Quanto aos motivos apontados para a prática da automedicação, o sintoma da febre foi relatado por 29 (58\%) dos entrevistados, seguido da tosse, por 18 (36\%); inflamação de garganta e dores em geral, 16 (32\%) cada; dor de cabeça e gripe, 13 (26\%);respectivamente, vômito, 7 (14\%); e cólica, 14 (28\%). Observa-se que a porcentagem total ultrapassa os $100 \%$, uma vez que no ato da entrevista foram apontados mais de um motivo para a utilização de cada fármaco. Também, foram utilizadas as expressões para descrever os sinais, sintomas e patologias, tais quais como afirmados pelos entrevistados.

No que diz respeito às justificativas para a automedicação, estas são apresentadas na Tabela 4.

Tabela 4 - Justificativas para a automedicação.

\begin{tabular}{lcc}
\hline Justificativas & Quantitativo & $\%$ \\
\hline Já estar acostumado a autoadministrar & 15 & 30 \\
Já possuir o remédio em casa & 12 & 24 \\
Aproveita a receita do irmão mais velho & 7 & 14 \\
Orientação do farmacêutico & 7 & 14 \\
O médico já receitou anteriormente & 5 & 10 \\
Por influência da televisão & 1 & 2 \\
Não justificaram & 3 & 6 \\
\hline Total & 50 & 100 \\
\hline
\end{tabular}

É bastante preocupante a detecção de que 15 (30\%) dos entrevistados fazem uso da automedicação com a justificativa de "já estar acostumado a autoadministrar", e que $12(24 \%)$ relatam "já possuir o remédio em casa". Essas falas demostram o desconhecimento dos pais ou responsáveis acerca dos efeitos colaterais, posologia e contraindicações dos fármacos, podendo acarretar consumo de medicamentos impróprios, doses errôneas, frequência inadequanda, período insuficiente ou demasiado de consumo, além de combinações inadequadas com outros fármacos, causando interações desconhecidas.

As demais justificativas, embora com menor quantitativo, ressaltam as práticas errôneas de utilização da mesma receita para outros episódios patológicos e a orietação do farmacêutico, o que pode trazer consequências como efeitos indesejáveis ou mascarar doenças evolutivas, representando, portanto, um problema a ser previnido já que nem sempre sintomas semelhantes requerem a mesma alternativa medicamentosa.

\section{DISCUSSÃO}

Os resultados do presente estudo corroboram outro constante da literatura ${ }^{11}$, em que a automedicação em crianças menores de cinco anos merece destaque, pois há maior probabilidade de reutilizarem antigas prescrições em relação às crianças mais velhas; ou seja, a automedicação ocorre em maior prevalência nessa faixa etária.

Um fator pertinente que pode contribuir para a reutilização de fármacos por menores de cinco anos está relacionado à condição fisiológica, já que, nessa idade, as crianças estão mais propensas a desenvolverem pequenos problemas de saúde, em especial, transtornos respiratórios ${ }^{12}$.

As crianças que se encontram na faixa etária de um a cinco anos necessitam, pois, de maior proteção e vigilância por parte dos pais e/ou responsáveis, porque também a noção de perigo ainda não está concretizada. Pelo contrário, estão fluentes à imaginação, à brincadeira, à curiosidade, à ânsia pelo conhecimento, características 
do comportamento infantil que, se não vigiados, podem induzir a sérios acidentes.

Em relação à renda dos pais e/ou responsáveis, resultado semelhante foi observado em um estudo ${ }^{13}$ realizado com crianças de zero a seis anos em que grande parte dos entrevistados provinham de famílias carentes, com rendimento mensal inferior a três salários mínimos. Percebe-se a influência que as condições socioeconômicas provocam sobre as práticas errôneas da automedicação, uma vez que as famílias não possuem recursos para a consulta e compra dos fármacos, optando, na sua grande maioria, pela autoadministração, alavancando, assim, os riscos à saúde das crianças.

No que concerne ao nível de escolaridade, os resultados desse estudo são concernentes com outro ${ }^{14}$ que mostra que os indivíduos mais graduados praticam com maior frequência a automedicação. Justifica-se que tal fato os auxilia na escolha do fármaco e os torna mais confiantes para automedicar, o que pode resultar em sérios danos à saúde da criança.

No que diz respeito aos fármacos autoadministrados, os achados desse estudo estão em concordância com outro constante da literatura, no qual os analgésicos e antitérmicos foram os fármacos não prescritos mais consumidos na comunidade estudada ${ }^{15}$.

Em outro estudo, ${ }^{16}$ os analgésicos e anti-inflamatórios não hormonais lideraram a preferência dos entrevistados (24\%), indicando que, de maneira geral, o hábito de automedicar está principalmente associado ao tratamento da dor. Analisando ainda outro estudo ${ }^{17} \mathrm{em}$ que os entrevistados praticaram a automedicação, pode-se citar o Paracetamol e a Dipirona, com uma frequência de $58,9 \%$ e os xaropes, com $31,1 \%$.

Em relação ao conhecimento a respeito dos fármacos autoadministrados encontrou-se na literatura que o limitado conhecimento em relação à sua ação farmacológica aumenta o risco de superdosagem, intoxicação e reações adversas, às quais os indivíduos estão expostos diante da prática da automedicação ${ }^{15}$.

Em outro estudo ${ }^{18}, 42,1 \%$ dos entrevistados demonstraram desconhecimento em relação ao fármaco envolvido. Dessa forma, como sugerem os dados, o desconhecimento acerca do fármaco não se torna um empecilho para a prática da automedicação. Faz-se, pois, necessário uma intervenção educativa juntos aos pais ou responsáveis, no sentindo de proporcionar esclarecimentos a respeito dos fármacos utilizados, assim como respeitar a dosagem baseada no peso e faixa etária pediátrica, questões essas contidas na prescrição.

No tocante aos motivos, os achados são preocupantes, uma vez que podem estabelecer o efeito causal para os prejuízos da automedicação, como 0 atraso no diagnóstico e na terapêutica adequada, reações adversas ou alérgicas e intoxicação. Alguns efeitos adversos podem ser mascarados, enquanto outros podem ser confundidos com os da própria patologia que provocou o consumo, criando novos problemas, podendo inclusive culminar com a internação hospitalar das crianças.

Em estudo constante da literatura ${ }^{14}$ evidenciou-se que o hábito da automedicação está associado à presença de sinais e sintomas menores; doenças ou condições crônicas mais graves estão associadas à utilização de fármacos prescritos. Os fármacos com ação anti-infecciosa e os fármacos para tosse, febre e resfriado são os mais utilizados em crianças, principalmente em função do elevado quantitativo de infecções respiratórias. Tais informações mostram-se em consonância com o estudo ora apresentado.

Esses dados ainda corroboram com o estudo ${ }^{17}$ em que $30,5 \%$ citaram a dor, especialmente a cefaleia, seguidos por $10,8 \%$ que citaram resfriados. Verifica-se também o uso de antibióticos, os quais, consumidos de forma inadequada, contribuem maciçamente para o mecanismo de resistência bacteriana em todo o mundo, sendo, portanto, um problema de saúde pública mundial.

Em relação às justificativas, um estudo ${ }^{19}$ destacou que, em $20,1 \%$ dos casos, a orientação para a automedicação decorreu da consulta na farmácia, fato comum que ocorre no Brasil. No entanto, o profissional farmacêutico, após a análise das informações do paciente, necessita realizar a intervenção adequada, incluindo a solicitação da apresentação da receita do fármaco.

Outro estudo ${ }^{13}$ identificou que aproximadamente $50 \%$ dos pais ou responsáveis realizaram a prática da automedicação, por já terem o costume de administrá-lo ou por já possuírem o receituário antigo. Tal fato pode ser explicado pela incorporação de práticas de tratamentos orientadas por profissionais de saúde, nem sempre adequadas para a situação na qual a criança se encontra.

Essa informação corrobora o estudo ${ }^{17}$ que diz respeito às justificativas para a automedicação, no qual $42,4 \%$ dos entrevistados responderam que seguem os conhecimentos anteriores para administrarem os fármacos e 32,4\% recorrem ao farmacêutico.

Alguns fatores como o fácil acesso aos fármacos e a propaganda em massa, aliados à comodidade e à busca pelo alívio imediato dos sintomas, também contribuem para a prática da automedicação ${ }^{18}$.

Nesse contexto, destaca-se a importância de educar de maneira crítica os profissionais da área da saúde, de modo que estes se tornem multiplicadores de informaç̧ões quanto ao uso racional de fármacos, salientando o risco da automedicação. Ressalta-se o papel do enfermeiro, bem como da equipe de enfermagem no processo da medicação. É imprescindível que esses profissionais disponibilizem seus conhecimentos, durante a orientação aos pacientes, de forma adequada e segura, reforçando o consumo consciente dos fármacos, bem como o elevado potencial de gravidade da automedicação. 
Espera-se que esse estudo contribua para alertar sobre o desconhecimento acerca dos fármacos autoadministrados às crianças, destacando, ainda, a importância da qualidade da orientação que a equipe de saúde precisa oferecer aos pais e responsáveis sob sua responsabilidade. A aliança com a Enfermagem pode e deve contribuir, auxiliando na construção de um processo de saúde com nível de excelência para a sociedade, favorecendo o conhecimento sobre os fármacos utilizados e, consequentemente, a interrupção da automedicação e a otimização da terapêutica.

0 estudo apresentou uma limitação advinda da não comparação da automedicação entre a população de diferentes Estratégias de Saúde da Família, uma vez que a região é composta por outras unidades de atendimento. Dessa maneira, é de grande importância o desenvolvimento de outros estudos.

\section{CONCLUSÕES}

Por meio da análise dos fármacos administrados, conhecimentos, motivos e justificativas dos pais e/ou responsáveis em relação à automedicação em crianças, emergiram dados relevantes, tais como o elevado quantitativo de fármacos, os quais são administrados, na maioria das vezes, com base em conhecimentos insuficientes. A febre e o costume da autoadministração se destacaram, respectivamente, como motivo e justificativa para a automedicação, ressaltando-se a gravidade da situação verificada na instituição em foco.

Portanto, urge implementar estratégias, sobretudo de cunho educativo, objetivando a conscientização dos pais e/ ou responsáveis acerca dos problemas oriundos da automedicação, a fim de evitar a perda da atividade terapêutica medicamentosa e, consequentemente, da segurança das crianças.

Ressalta-se, também, a extrema importância de aprofundar a discussão sobre o papel do enfermeiro na efetiva orientação à sociedade quanto aos fármacos utilizados, pois, por meio de sua atuação educativa, haverá um conhecimento mais profundo sobre os medicamentos utilizados e, consequentemente, uma otimização da terapêutica.

\section{REFERÊNCIAS}

1. Pfaffenbach G. Automedicação em crianças: um problema de saúde pública. Rev. paul. pediatr. 2010 jun; 28(3): 260-1.

2. Lima GB, Nunes LCC, Barros JAC. Uso de medicamentos armazenados em domicílio em uma população atendida pelo programa saúde da família. Ciênc. saúde coletiva. 2010 jan; 15(3): 3517-22.
3. Wertheimer Al, Serradell J. A discussion paper on self-care and its implications for pharmacists. Pharm Wordl Sci. 2008 jan; 30(4): 309-15.

4. Albarrán KF, Zapata LV. Analysis and quantification of selfmedication patterns of customers in community pharmacies in southern Chile. Pharm World Sci. 2008 aug; 30(6): 863-8.

5. Tourinho FSV, Bucaretchi F, Stephan C, Cordeiro R. Home medicine chests and their relationship with self-medication in children and adolescents. J. pediatr. 2008 jul; 84(5): 416-22.

6. Margonato FB, Thomson Z, Paoliello MMB. Determinantes nas intoxicações medicamentosas agudas na zona urbana de um município do Sul do Brasil. Cad. saúde pública. 2008 fev; 24(2): 333-41.

7. Oliveira EA, Bertoldi AD, Domingues MR, Santos IS, Barros AJD. Uso de medicamentos no nascimento aos dois anos: Coorte de Nascimentos de Pelotas, RS, 2004. Rev. saúde pública. 2010 fev; 44(4): 591-600.

8. Gil AC. Como elaborar projeto de pesquisa. São Paulo: Atlas; 2002.

9. Barros ARR, Griep RH, Rotenberg L. Self-medication among nursing workers from public hospitals. Rev. latinoam. enferm. 2009 nov/dez; 17(6): 1015-22.

10. Ministério da Saúde (Brasil). Conselho Nacional de Saúde. Diretrizes e normas regulamentadoras de pesquisa envolvendo seres humanos. Resolução n. 196, de 10 de outubro 1996. Brasília; 1996.

11. Beckhauser GC, Souza JM, Valgas C, Piovezan AP, Galato D. Utilização de medicamentos na pediatria: a prática de automedicação em crianças por seus responsáveis. Rev. paul. pediatr. 2010 jun; 28(3): 262-8.

12. Oliveira ICS. Conhecimento da família acerca da saúde da criança de 1 a 5 anos em uma comunidade ribeirinha: subsídios para a enfermagem pediátrica. Esc. Anna Nery Rev. Enferm. 2009 out; 13(4): 750-6.

13. Carvalho DC, Trevisol FS, Menegali BT, Trevisol DJ. Uso de medicamentos em crianças de zero a seis anos matriculadas em creches de Tubarão, Santa Catarina. Rev. paul. pediatr. 2008 abr; 26(3): 23-44.

14. Silva IM, Catrib AMF, Matos VC, Gondim APS. Automedicação na adolescência: um desafio para a educação em saúde. Ciênc. saúde coletiva. 2011 nov; 16(1):1651-60.

15. Cossío MG. Nuevas etiquetas de medicamentos para apoyar la automedicación en México. El caso de un analgésico pediátrico. Salud Pública de México. 2008 sep; 50(4): 453-462.

16. Aquino DS, Barros JAC, Silva MDP. A automedicação e os acadêmicos da área de saúde. Ciênc. saúde coletiva. 2010 jun; 15(5): 2533-8. 
17. Cancelier ACL, Kubo TK, Pizzol FD. Autoemdicação em crianças com Rinofaringite Aguda. Arq. catarin. med. 2006; 35(2): 35-40.

18. Lessa MA, Bochner R. Análise das internações hospitalares de crianças menores de um ano relacionadas a intoxicações e efeitos adversos de medicamentos no Brasil. Rev. bras. epidemiol. 2008 nov; 11(4): 660-74.

19. Carvalho MF, Pascom AR, Souza-Junior PR, Damacena GN, Szwarcwald CL. Utilization of medicines by the Brazilian population, 2003. Cad. saúde pública. 2005; 21 Suppl:S100-8. 